\section{Introduction to Risk Assessment Terminology}

Andrea Serraino

Dipartimento di Scienze Mediche Veterinarie, Alma Mater Studiorum Università di Bologna, Ozzano dell'Emilia (BO), Italy

Terminology is the discipline that systematically studies concepts and their denominations, that is to say the terms in use in the specialistic languages of a science, a technical sector, an occupational activity or a social group in order to describe or prescribe its correct use. The term terminology not only designates a discipline, but also the whole of terms which represent a conceptual system in a specific field. (ISO, 2000).

Twenty years have passed since Ahl et al. (1993), in the Révue Scientifique et Technique of the then Office International des Epizooties, today's Animal Health World Organization, maintained that because of its continuous and rapid evolution and partly for the fusion of various scientific disciplines the Nomenclature in risk analysis is in a state of confusion.

Their call was immediately answered by a FA0/0MS expert mixed Consultation that - on the occasion of the $41^{\text {st }}$ session of the Commission of the Alimentarius Codex executive Committee - faced, among other things, the issue of terminology thus acknowledging the necessity of uniform definitions for different terms utilised in Risk Analysis (FAO/OMS,1995).

With the publication of Nomenclature proposée pour l'analyse $d u$ risque in the Epidémiologie et Santé Animal journal, and with a view to make the communication easier in the field both of food safety and of importation of animals and their products, some INRA and Maisons-Alfort researchers are getting along with the analysis of the terms utilised in the Risk Analysis field assessing their correspondence with les expressions anglaises (Cerf et al., 1996).

Reij et al. (2000), in a contribution entitled Critical Notes on Microbiological Risk Assessment of Food, reasserted how a major problem with risk assessment is confusion about terminology stressing that many publications quoting the term Risk Analysis in the title have no relevance at all to what is meant by this term by the Alimentarius Codex definitions. The term risk is often confused with the term probability and further used with the meaning of hazard.

More recently, in a letter to the Editor in the prestigious Risk Analysis journal, while analysing the definition differences of the term risk between food safety and animal health, areal linguistics Prof. Oliver Cerf has laid the stress on the fact that the terminology problem is, furthermore, at the bottom of possible distortions of risk managers' decisionmaking processes. (Cerf, 2008).

The sciences analysing and describing risks are relatively new. They are in phase of development just like the terminology associated to the them is in phase of evolution (Møller Christensen et al., 2003).

The language utilized in Risk Analysis is, without any doubt, a special language, a whole of linguistic media (of lexical, morphological, phraseological and syntactic kind) adopted in a conventional and consensual way by a group of individuals working in the same field for the exchange and divulgation of information and knowledges connected to it. This language suits the needs for optimal comprehension at specialist level by giving precision, univocality and concision guarantees.

At the same time it is a language which changes rapidly, if only for the borrowing of terms from several disciplines and technologies.

The widening of a discipline knowledge inevitably also brings along the development of the relating special terminology. Novelties need meaningful, univocal and, if possible, clear terms so that it is often essential to create a new term (i.e. elicitation) in order to designate a well-defined special concept.

For these reasons the Editorial Board of the Italian Journal of Food Safety decided, on $15^{\text {th }}$ November 2013, to open a new section of the Journal that, through the collection and explanation of the terms utilized in the field of Risk Analysis (Assessment, Management and Communication), aim the creation of a reasoned term dictionary in order to foster and improve the diffusion of literacy as far as the term risk is concerned (the new term to be coined might be Risk Literacy paraphrasing the already existing one of Health Literacy). The section is open to contributions of all Authors and manuscripts will be published in English and Italian language; manuscripts will receive high speed revision and publication.
Correspondence: Andrea Serraino, Dipartimento di Scienze Mediche Veterinarie, Alma Mater Studiorum - Università di Bologna, Ozzano dell'Emilia (B0), Italy.

Tel.+39.051.2097332 - Fax: +39.051.2097346.

E-mail: andrea.serraino@unibo.it

Key words: Risk analysis, Terminology, Dictionary.

Received for publication: 4 December 2013.

Accepted for publication: 5 December 2013.

This work is licensed under a Creative Commons Attribution 3.0 License (by-nc 3.0).

(C) Copyright A. Serraino, 2014

Licensee PAGEPress, Italy

Italian Journal of Food Safety 2014; 3:2183

doi:10.4081/ijfs.2014.2183

\section{References}

Ahl AS, Acree JA, Gipson PS, McDowell RM, Miller L, McElvaine MD, 1993 Standardisation of nomenclature for animal health risk analysis. Rev Sci Tech 12:1045-1053.

Cerf 0, 2008. Current definitions of risk for food safety and animal health allow risk assessments to provide substantially different outcomes. Risk Anal 28:811-3.

Cerf 0, Sanaa M, Dufour B, Toma B, 1996. [Nomenclature proposèe pour l'analyse de risque en santé humaine et animale]. [Article in French]. Rev Epid San Anim 30:35-43.

FAO/OMS, 1995. [Application de l'analyse des risques dans le domaine des normes alimentaires. Rapport de la consultation mixte d'experts FA0/0MS]. [Paper in French]. Consultation mixte d'experts, Geneve, Suisse, pp. 1-43.

ISO, 2000. Terminology work. Vocabulary. Part 1: theory and application. ISO norm 10871:2000. International Standardization Organization ed., Geneva, Switzerland.

Møller Christensen F, Andersen 0, Duijm NJ, Harremoës P, 2003. Risk terminology-a platform for common understanding and better communication. J Hazard Mater 103:181-203.

Reij MW, Van Schothorst M, 2000. Critical notes on microbiological risk assessment of food. Braz J Microbiol 31:1-8. 